\title{
EFEITO DA CARGA PENDENTE NA QUALIDADE DE FRUTOS DE LARANJEIRA 'VALÊNCIA'
}

\author{
THIAGO FRANCO DUARTE ${ }^{2}$, ILANA URBANO BRON ${ }^{3}$, RAFAEL VASCONCELOS RIBEIRO ${ }^{3}$, \\ EDUARDO CARUSO MACHADO ${ }^{3}$, PAULO MAZZAFERA ${ }^{4}$, MILTON MASSAO SHIMIZU $^{5}$
}

RESUMO-Algumas espécies de citros apresentam produção irregular ao longo dos anos. Além da safra irregular, a alternância de produção pode interferir na qualidade dos frutos, característica cada vez mais valorizada pelo mercado citrícola. O objetivo do trabalho foi avaliar o efeito da carga pendente na qualidade dos frutos da laranjeira 'Valência'. O experimento foi conduzido com laranjeiras 'Valência' enxertadas em tangerineiras 'Cleópatra' em condição de campo. Em janeiro de 2007, metade das plantas teve todos os seus frutos retirados, enquanto a outra metade permaneceu intacta. As plantas que tiveram seus frutos retirados apresentaram, em setembro de 2007, floração mais intensa e, portanto, uma Alta Carga de frutos (AC, 752 frutos/árvore) em 2008, quando comparadas às plantas que não tiveram seus frutos retirados, que apresentaram Baixa Carga de frutos (BC, 317 frutos/árvore). Os frutos maduros, colhidos em dezembro de 2008, foram analisados quanto à massa, teor de sólidos solúveis, acidez titulável, espessura e cor da casca, teor de suco e número de sementes. Na safra seguinte, de 2009, as avaliações das características físicoquímicas dos frutos foram repetidas nas mesmas árvores, mas durante quatro momentos entre o período de frutificação e a colheita, em novembro de 2009. Na safra de 2008, houve diferença na massa individual dos frutos com valores de 172 e $158 \mathrm{~g}$ nas plantas $\mathrm{BC}$ e AC, respectivamente. O teor de sólidos solúveis, acidez titulável, teor de suco nos frutos, espessura da casca e o índice tecnológico foram semelhantes entre os tratamentos, nas safras de 2008 e 2009. Entretanto, vale considerar que, como a produção de frutos nas plantas AC, na safra de 2008, foi 2,2 vezes maior se comparada às das plantas BC (AC: 2,9 caixas/planta e BC: 1,3 caixa/planta), a quantidade total de sólidos solúveis produzida por planta também foi maior. Não houve influência da carga pendente de frutos no teor de açúcares (glicose, frutose e sacarose) no suco e na cor da casca durante o desenvolvimento dos frutos. Apesar de reduzir a massa do fruto, a diferença de carga pendente observada em laranjeira 'Valência' não influenciou na qualidade dos frutos quando considerado, como destino da fruta, a indústria citrícola.

Termos para indexação: Citrus sinensis, carboidratos, laranja, alternância de produção.

\section{EFFECT OF CROP LOADING ON QUALITY OF 'VALENCIA' ORANGE FRUIT}

\begin{abstract}
Some citrus species show irregular production over the years. Besides the irregular crop yield, alternate bearing may affect the fruit quality, a characteristic that is increasingly valued by the citrus market. The aim of the work was to evaluate the effect of crop load on fruit quality of 'Valência' orange trees. The experiment was carried out under field conditions with 'Valência' orange scions grafted on 'Cleópatra' mandarin rootstocks. In January 2007, half of the plants were defruited, while the other half remained intact. Plants that had their fruit removed showed in September 2007 more intense flowering, and therefore a high fruit load (HL, 752 fruits/tree) in 2008, compared to intact plants showed low fruit load (LL, 317 fruits/tree). The fruits harvested in December 2008 were analyzed considering weight, soluble solids, titratable acidity, peel thickness, juice percentage, number of seeds and peel color. In the next crop, in 2009, the evaluations of physical and chemical characteristics of fruits were carried out in the same trees but during four moments between fruit development and harvest in November 2009. Fruit harvest in 2008 had different individual weight with values of 172 and $158 \mathrm{~g}$ for LL and HL plants, respectively. The soluble solids, titratable acidity, percentage of juice, peel thickness and technological index was similar between treatments in 2008 and 2009. However as fruit production in HL plants was 2.2 times higher than in LL plants in 2008 (AC: 2,9 boxes/plant and BC: 1,3 boxes/plant), total soluble solids produced per plant was also higher. Crop load did not affect the sugar content (glucose, fructose and sucrose) in juice and skin color during fruit development. Although it reduced the fruit weight, the difference in crop load observed in 'Valência' orange had no influence on fruit quality when considered the citrus industry as fruit destination.
\end{abstract}

Index terms: Citrus sinensis, carbohydrates, orange, alternate bearing.

'(Trabalho 181-10). Recebido em: 30-07-2010. Aceito para publicação em: 05-01-2011.

${ }^{2} \mathrm{Eng}^{\circ} \mathrm{Agr}^{\circ}$, M. Sc., Instituto Agronômico de Campinas - IAC, C.P 28, CEP 13012-970, Campinas-SP. E-mail: thiagof.duarte@hotmail.com ${ }^{3}$ Eng $^{a}$ Agra , Dra, Pesquisador do Instituto Agronômico de Campinas - IAC, C.P 28 CEP 13012-970, Campinas-SP. E-mails: ilana@iac.sp.gov.br; rafael@iac.sp.gov; caruso@iac.sp.gov

${ }^{4} \mathrm{Eng}^{\mathrm{O}} \mathrm{Agr}^{\circ}$, Dr, Professor da Universidade Estadual de Campinas, C.P 6109 CEP 13083-970, Campinas-SP. E-mail: pmazza@unicamp.br ${ }^{5}$ Biólogo, Dr., Universidade Estadual de Campinas, C.P 6109 CEP 13083-970, Campinas-SP. E-mail: massao_shimizu@yahoo.com.br 


\section{INTRODUÇÃO}

Os citros produzem grande quantidade de flores durante a floração. Entretanto, apenas uma pequena proporção de flores produzidas dá origem a frutos maduros (BUSTAN; GOLDSCHMIDT, 1998). As flores e os frutos cítricos dependem, em grande parte, do fornecimento de fotoassimilados de outras partes da planta para se fixar e desenvolver (VU et al., 1985). A diminuição nos níveis de carboidratos foliares durante o período de floração e fixação dos frutos (GONZALEZ-FERRER et al., 1984) demonstra que essas reservas são utilizadas durante o desenvolvimento reprodutivo, existindo correlação positiva entre o teor de carboidratos e a floração (GOLDSCHMIDT; GOLOMB, 1982; IGLESIAS et al., 2003) e frutificação (SANZ et al., 1987).

Mais de $16 \%$ da matéria seca total de uma árvore de citros podem ser exportadas para os frutos em anos de alta produção (GOLDSCHMIDT;GOLOMB, 1982). Grande quantidade de frutos produzidos demanda, portanto, uma quantidade significativa de energia e elementos estruturais advindos da hidrólise de carboidratos. Essa demanda é acentuada quanto maior for o tempo de permanência dos frutos na planta, como no caso da laranja 'Valência', que apresenta longo período de desenvolvimento da antese ao amadurecimento (MONSELISE; GOLDSCHMIDT, 1982). Além da floração e frutificação, a quantidade de frutos e, por consequência, a disponibilidade de carboidratos afetam a qualidade dos frutos. Geralmente, em anos de alta produção, os frutos produzidos são pequenos, de qualidade inferior, provavelmente devido à maior competição por reservas. O raleio manual de frutos é uma técnica que tem com objetivo produzir frutos de melhor qualidade e, consequentemente, de maior valor comercial. Assim, esta técnica evidencia o efeito da disponibilidade de reserva na qualidade dos frutos. Em tangerineira 'Ponkan' (Citrus reticulata Blanco), o raleio aumentou o diâmetro e a massa média dos frutos (RUFINI; RAMOS, 2002), todavia não alterou a qualidade interna dos frutos, como teor de sólidos solúveis, acidez titulável, açúcares totais e rendimento de suco.

Vários trabalhos com laranjeira 'Valência' e outros citros foram conduzidos no Hemisfério Norte. Em nossas condições, a relação entre o acúmulo de reservas, crescimento e a qualidade dos frutos ainda é muito pouco explorada.

O objetivo deste trabalho foi testar a hipótese de que a maior carga pendente na laranjeira 'Valência' prejudica a qualidade final dos frutos, realizando experimento de campo em uma importante região citrícola do Estado de São Paulo.

\section{MATERIAL E MÉTODOS}

O experimento foi realizado em Cordeirópolis, São Paulo (22³2'S; 47²7'O; 639 m de altitude). Foram utilizadas laranjeiras 'Valência' [Citrus sinensis (L.) Osbeck], enxertadas em tangerineira 'Cleópatra' (Citrus reticulata Blanco), com 20 anos de idade e plantadas no espaçamento de $8 \times 5 \mathrm{~m}$, com orientação da linha de plantio no sentido norte-sul. Em janeiro de 2007, metade das plantas teve todos os seus frutos retirados, enquanto a outra metade permaneceu intacta. $\mathrm{O}$ delineamento adotado foi em blocos ao acaso, com cinco repetições, e os tratamentos foram dois níveis de carga: Alta Carga (AC) e Baixa Carga (BC) de frutos. As plantas AC (752 frutos/árvore) foram aquelas que tiveram todos os seus frutos retirados e apresentaram floração mais intensa em 2007 e alta carga de frutos em 2008, quando comparadas às plantas $\mathrm{BC}$ (317 frutos/ árvore), que não tiveram seus frutos retirados (Figura 1). Cada bloco continha 6 plantas, 3 desbastadas e 3 intactas, sendo cada parcela composta por três plantas. Os frutos colhidos da safra de 2008 foram analisados quanto ao teor de sólidos solúveis (SS), determinado com refratômetro digital portátil (Atago, PAL-1); acidez titulável (AT), obtida titulando-se $10 \mathrm{~mL}$ de suco diluídos em $90 \mathrm{~mL}$ de água destilada com hidróxido de sódio $(0,1 \mathrm{~N})$ até que a solução atingisse $\mathrm{pH} 8,1$, com os resultados expressos em $\mathrm{g}$ de ácido cítrico por $100 \mathrm{~mL}$ de suco (LADANYA, 2008); rendimento de suco, determinado pela relação entre a massa do suco e a massa do fruto; espessura da casca, medida com paquímetro digital; e número de sementes de cada fruto.

No ano agrícola de 2008/2009, foram realizadas avaliações mensais não destrutivas do crescimento e da cor dos frutos. Para ambas as medidas, utilizaram-se 20 frutos/planta (10 localizados no quadrante leste da copa das plantas e outros 10 no quadrante oeste) em cada parcela. A avaliação de crescimento iniciou-se quando os frutos atingiram $5 \mathrm{~mm}$ de diâmetro, medindo-se o comprimento no sentido equatorial, na região de maior diâmetro. A determinação da cor da casca $\left(\mathrm{H}^{\circ}\right)$ foi iniciada quando os frutos tinham aproximadamente $50 \mathrm{~mm}$ de diâmetro, posicionando-se o colorímetro (Minolta CR-300) na região de maior diâmetro e obtendo-se uma leitura por fruto. Nas avaliações de crescimento e cor dos frutos, foram utilizados sempre os mesmos frutos. As avaliações das características físico-químicas dos frutos e também do teor de carboidratos no suco foram realizadas em quatro momentos (abril, julho, 
outubro e novembro de 2009, quando os frutos foram colhidos). Vinte frutos/planta (10 do quadrante leste e 10 do oeste) foram avaliados em cada parcela, e as mesmas variáveis e procedimentos foram adotados na análise realizada nos frutos colhidos em 2008.

O suco extraído dos frutos foi congelado e armazenado em freezer $\left(-20^{\circ} \mathrm{C}\right)$ até o momento das análises de carboidratos. A concentração de sacarose, frutose e glicose do suco foi determinada por cromatografia líquida de alta eficiência, usando coluna Carbopac PA10 (Dionex), 40mM NaOH como fase móvel no fluxo de $1,5 \mathrm{~mL} / \mathrm{min}$. A detecção foi feita com detector eletroquímico (STANCATO et al., 2001).

Os dados foram submetidos à análise de variância (teste F) e comparação de médias, pelo teste de Tukey, considerando-se 5\% de probabilidade.

\section{RESULTADOS E DISCUSSÃO}

Na safra de 2008 (colheita em 12-12-2008), a diferença de carga pendente foi de 2,2 vezes maior nas plantas $\mathrm{AC}$ em relação às plantas $\mathrm{BC}$, que produziram em média 2,9 e 1,3 caixas por planta, respectivamente (Figura 3A). Já na safra de 2009 (colheita em 10-112009), a carga de frutos foi estatisticamente igual entre as plantas AC e BC (Figura 3B), apesar de diferenças na floração.

Não houve influência da carga de frutos na acidez do suco. Nos frutos colhidos em 2008, a acidez foi de $0,71 \%$ nas plantas $\mathrm{BC}$ e de $0,68 \%$ para as plantas AC (Tabela 1). Durante o desenvolvimento dos frutos, a acidez decresceu gradualmente nas plantas AC e BC, apresentando na colheita de 2009 valores variando entre $0,68 \%$ e $0,72 \%$, independentemente da carga de frutos (Tabela 1). Em laranjas, o ácido cítrico pode atingir $4 \%$ nos estádios iniciais de desenvolvimento do fruto, diminuindo com a maturação (RODRIGO; ZACARIAS, 2006).

Os frutos cítricos apresentam uma quantidade de ácidos orgânicos que, em balanço com os teores de açúcares, representam um importante atributo de qualidade. Para a laranja 'Valência', o valor aceitável de sólidos solúveis é de $11,8^{\circ}$ Brix (FIGUEIREDO, 1991). Os frutos da safra de 2008 apresentaram valores de $12,5^{\circ}$ Brix, independentemente do tratamento (Tabela 1). Estes resultados indicam a ausência de efeito dos tratamentos neste importante atributo de qualidade. A concentração de açúcares no fruto tende a aumentar gradativamente com seu desenvolvimento (LADANIYA, 2008), podendo-se avaliar esse atributo pelo teor de sólidos solúveis. O incremento nos sólidos solúveis dos frutos foi similar entre os tratamentos, variando de $7,7^{\circ}$ Brix a $11,1^{\circ}$ Brix nas plantas BC e de $7,8^{\circ}$ Brix a $11,4^{\circ}$ Brix nas plantas AC, no ano agrícola de 2008/2009 (Tabela 1).

Sabe-se que o acúmulo de açúcares no suco é influenciado pela relação fonte-dreno e, deste modo, esperava-se que plantas com maior carga de frutos acumulassem menor quantidade de açúcares nos frutos. Entretanto, nos frutos da safra de 2008, na qual a diferença de carga pendente era na ordem de 2,2 vezes maior nas plantas $\mathrm{AC}$ em relação às plantas $\mathrm{BC}$, os frutos provenientes das plantas $\mathrm{AC} \mathrm{e}$ $\mathrm{BC}$ acumularam quantidades semelhantes de frutose, glicose e sacarose no suco (Figura 2). Este resultado sugere uma possível limitação na capacidade de dreno (frutos) ou da fonte (folhas) de laranjeiras 'Valência', podendo ainda ser uma evidência de que a magnitude e a diferença de carga pendente não foram suficientes para induzir alterações nos teores destes açúcares.

A maturação das laranjas pode ser acompanhada pela relação entre os sólidos solúveis e a acidez (ratio) do suco (LADANIYA, 2008). Independente do tratamento, os frutos colhidos na safra de 2008 e na safra de 2009 apresentaram valores de ratio aceitáveis (Tabela 1), estando próximo do ratio 14, indicado para laranjas 'Valência' (NONINO, 1995). Além disso, a variação da carga de frutos não alterou esta variável ao longo do desenvolvimento dos frutos.

Para a produção de sucos concentrados, a matéria-prima é qualificada pelo índice tecnológico (IT), parâmetro que expressa a quantidade de sólidos solúveis por caixa de laranja $(40,8 \mathrm{~kg})$. Tanto o teor de suco quanto o de sólidos solúveis dos frutos da safra de 2008 e 2009 não foram influenciados pela carga pendente (Tabela 1). O índice tecnológico foi semelhante entre as plantas BC e AC na safra de 2008 e 2009, em média 2,6 (dados não apresentados). Esse valor é apropriado para laranjas cujo IT ideal varia de 2,49 a 2,86 $\mathrm{kg}$ de SS caixa ${ }^{-1}$ (DI GIORGI et al., 1990). Outro ponto relevante é a quantidade total de sólidos solúveis produzida por planta, que foi maior nas plantas AC por apresentarem mesmo IT e maior produção de frutos (Figura 3A).

Os frutos das plantas BC, na safra de 2008, alcançaram massas maiores, se comparados aos frutos das plantas AC, mas com teores de suco e sólidos solúveis similares (Tabela 1). Gallasch (1978) observou que frutos de laranjeira 'Valência' provenientes de plantas com baixa carga pesaram até 53\% a mais se comparados com os frutos das plantas com alta carga. De fato, a massa dos frutos e o seu tamanho final são resultantes do acúmulo de matéria seca e de água, sendo este acúmulo determinado pela força de dreno do fruto e pelo suprimento de metabólitos. O 
fornecimento de metabólitos, por sua vez, depende da disponibilidade e da competição entre os drenos em desenvolvimento. Assim, quanto maior o número de frutos, maior a competição por metabólitos e menor será o seu tamanho e sua massa, tornando a massa dos frutos inversamente proporcional à carga pendente (GUARDIOLA, 1992).

À medida que os frutos se desenvolvem, a espessura da casca diminui. Este atributo reflete principalmente no rendimento de suco, pois, quanto menor a espessura da casca, maior será o aproveitamento do produto (CHITARRA; CHITARRA, 1990). A variação da carga pendente observada não alterou essa característica das laranjas (Tabela 1), assim como a cor da casca dos frutos. Observa-se que, na medida em que os frutos se desenvolveram, o ângulo de cor $\left(\mathrm{H}^{\circ}\right)$ diminui, indicando coloração mais amarela, independentemente do tratamento (Figura 4). A coloração externa de frutos cítricos é um dos principais atributos de qualidade para a aceitação dos consumidores (RODRIGO; ZACARIAS, 2006). O desenvolvimento da coloração externa dos frutos é resultado de mudanças no balanço do conteúdo de carotenoides e de clorofilas (RODRIGO; ZACARIAS, 2006). Sabe-se que os atributos de qualidade de frutos de laranja, como cor, textura e sabor, são influenciados em parte pela disponibilidade de carboidratos (LADANIYA, 2008).
Com relação ao número de sementes, a quantidade por fruto não diferiu estatisticamente nas safras de 2008 e 2009 (Tabela 2). No entanto, quando consideramos a quantidade de semente na árvore, as plantas AC produziram quase três vezes mais sementes quando comparadas às plantas $\mathrm{BC}$, na safra de 2008 (Figura 5). As sementes em desenvolvimento são uns dos principais locais de síntese de giberelina, hormônio inibidor da floração nos citros (GUARDIOLA et al., 1982). Considerando que as giberelinas produzidas nas sementes podem ser exportadas para os ramos e gemas (MOSS, 1971), a alta produção de sementes por planta poderia explicar a menor floração na safra seguinte.

Apesar de haver evidências de que, em anos de alta produção, os frutos produzidos são pequenos e de qualidade inferior, provavelmente devido à grande competição pelo substrato (WHEATON, 1986), no presente trabalho, a carga pendente alterou apenas a massa dos frutos, quando a diferença de carga entre os tratamentos era da ordem de 2,2 vezes (AC: 2,9 caixas/planta e BC: 1,3 caixa/planta). Nos frutos da safra de 2009, na qual a quantidade de frutos entre as plantas AC e BC era semelhante, não houve diferença na qualidade dos frutos.

TABELA 1 - Sólidos solúveis ( ${ }^{\circ}$ Brix), acidez (\% ácido cítrico), ratio (SS: AT), teor de suco (\%), massa dos frutos $(\mathrm{g})$ e espessura da casca $(\mathrm{mm})$ de laranjas 'Valência' em plantas $\mathrm{AC}$ e BC. \pm indicam o erro-padrão $(\mathrm{n}=5)$.* $^{*}$

\begin{tabular}{|c|c|c|c|c|c|c|}
\hline \multirow{2}{*}{ Datas de Avaliação } & \multicolumn{2}{|c|}{ Sólidos Solúveis ( $\left.{ }^{\circ} \mathrm{Brix}\right)$} & \multicolumn{2}{|c|}{ Acidez (\% ácido cítrico) } & \multicolumn{2}{|c|}{ Ratio (SS: AT) } \\
\hline & $\mathrm{BC}$ & $\mathrm{AC}$ & $\mathrm{BC}$ & $\mathrm{AC}$ & $\mathrm{BC}$ & $\mathrm{AC}$ \\
\hline $12-12-2008$ & $12,5 \pm 0,3 \mathrm{a}$ & $12,5 \pm 0,2 \mathrm{a}$ & $0,71 \pm 0,1 \mathrm{a}$ & $0,68 \pm 0,01 \mathrm{a}$ & $17,6 \pm 0,5 \mathrm{a}$ & $18,5 \pm 0,6 \mathrm{a}$ \\
\hline 22-04-2009 & $7,7 \pm 0,9 \mathrm{a}$ & $7,8 \pm 0,8 \mathrm{a}$ & $2,59 \pm 0,4 \mathrm{a}$ & $2,42 \pm 0,25 \mathrm{a}$ & $3,2 \pm 0,3 \mathrm{a}$ & $3,3 \pm 0,2 \mathrm{a}$ \\
\hline 01-07-2009 & $9,2 \pm 0,2 \mathrm{a}$ & $9,7 \pm 0,5 \mathrm{a}$ & $1,39 \pm 0,1 \mathrm{a}$ & $1,46 \pm 0,02 \mathrm{a}$ & $6,5 \pm 0,3 \mathrm{a}$ & $6,7 \pm 0,1 \mathrm{a}$ \\
\hline 21-10-2009 & $10,3 \pm 0,3 \mathrm{a}$ & $11,3 \pm 0,3 \mathrm{a}$ & $0,81 \pm 0,1 \mathrm{a}$ & $0,84 \pm 0,05 \mathrm{a}$ & $13,0 \pm 0,5 \mathrm{a}$ & $13,6 \pm 0,5 \mathrm{a}$ \\
\hline $10-11-2009$ & $11,2 \pm 0,2 \mathrm{a}$ & $11,4 \pm 0,2 \mathrm{a}$ & $0,68 \pm 0,1 \mathrm{a}$ & $0,72 \pm 0,02 \mathrm{a}$ & $16,4 \pm 0,9 \mathrm{a}$ & $16,0 \pm 0,5 \mathrm{a}$ \\
\hline \multirow{2}{*}{ Datas de Avaliação } & \multicolumn{2}{|c|}{ Teor de suco $(\%)$} & \multicolumn{2}{|c|}{ Massa dos frutos (g) } & \multicolumn{2}{|c|}{ Espessura da casca $(\mathrm{mm})$} \\
\hline & $\mathrm{BC}$ & $\mathrm{AC}$ & $\mathrm{BC}$ & $\mathrm{AC}$ & $\mathrm{BC}$ & $\mathrm{AC}$ \\
\hline $12-12-2008$ & $55,2 \pm 0,6 \mathrm{a}$ & $52,3 \pm 0,5 \mathrm{a}$ & $172 \pm 4 \mathrm{a}$ & $158 \pm 5 b$ & $4,2 \pm 0,0 \mathrm{a}$ & $4,2 \pm 0,0 \mathrm{a}$ \\
\hline 22-04-2009 & $53,6 \pm 2,3 \mathrm{a}$ & $51,0 \pm 0,8 \mathrm{a}$ & $141 \pm 3 a$ & $143 \pm 2 \mathrm{a}$ & $4,4 \pm 0,1 \mathrm{a}$ & $4,6 \pm 0,1 \mathrm{a}$ \\
\hline 01-07-2009 & $55,4 \pm 0,6 \mathrm{a}$ & $54,8 \pm 2,6 \mathrm{a}$ & $160 \pm 4 \mathrm{a}$ & $159 \pm 4 \mathrm{a}$ & $4,0 \pm 0,1 \mathrm{a}$ & $4,3 \pm 0,1 \mathrm{a}$ \\
\hline 21-10-2009 & $56,6 \pm 0,8 \mathrm{a}$ & $58,0 \pm 0,2 \mathrm{a}$ & $190 \pm 5 \mathrm{a}$ & $182 \pm 4 \mathrm{a}$ & $5,2 \pm 0,3 \mathrm{a}$ & $4,8 \pm 0,1 \mathrm{a}$ \\
\hline $10-11-2009$ & $56,2 \pm 0,6 \mathrm{a}$ & $55,2 \pm 0,8 \mathrm{a}$ & $172 \pm 4 \mathrm{a}$ & $176 \pm 7 \mathrm{a}$ & $4,2 \pm 0,2 \mathrm{a}$ & $4,3 \pm 0,1 \mathrm{a}$ \\
\hline
\end{tabular}

Letras iguais na mesma linha, dentro do mesmo atributo, não se diferem estatisticamente, pelo teste de Tukey $(\mathrm{p}<0,05)$.

* BC: plantas com Baixa Carga de frutos; AC plantas com Alta Carga de frutos. 
TABELA 2 - Quantidade de sementes/frutos de laranjas 'Valência' em plantas BC e AC. \pm indicam o erro-padrão $(\mathrm{n}=5)$. *

\begin{tabular}{ccc}
\hline \multirow{2}{*}{ Datas de Avaliação } & \multicolumn{2}{c}{ Sementes/fruto $\left(\right.$ unidade $\left.^{-1}\right)$} \\
& $\mathrm{BC}$ & $\mathrm{AC}$ \\
\hline $12-12-2008$ & $7,0 \pm 0,3 \mathrm{a}$ & $8,0 \pm 0,4 \mathrm{a}$ \\
$22-04-2009$ & $7,5 \pm 0,2 \mathrm{a}$ & $7,0 \pm 0,3 \mathrm{a}$ \\
$01-07-2009$ & $6,5 \pm 0,3 \mathrm{a}$ & $7,0 \pm 0,3 \mathrm{a}$ \\
$21-10-2009$ & $7,3 \pm 0,4 \mathrm{a}$ & $6,6 \pm 0,3 \mathrm{a}$ \\
$10-11-2009$ & $7,6 \pm 0,4 \mathrm{a}$ & $6,6 \pm 0,4 \mathrm{a}$ \\
\hline
\end{tabular}

Letras iguais na mesma linha não se diferem estatisticamente, pelo teste de Tukey $(\mathrm{p}<0,05)$. * BC: plantas com Baixa Carga de frutos; AC plantas com Alta Carga de frutos.

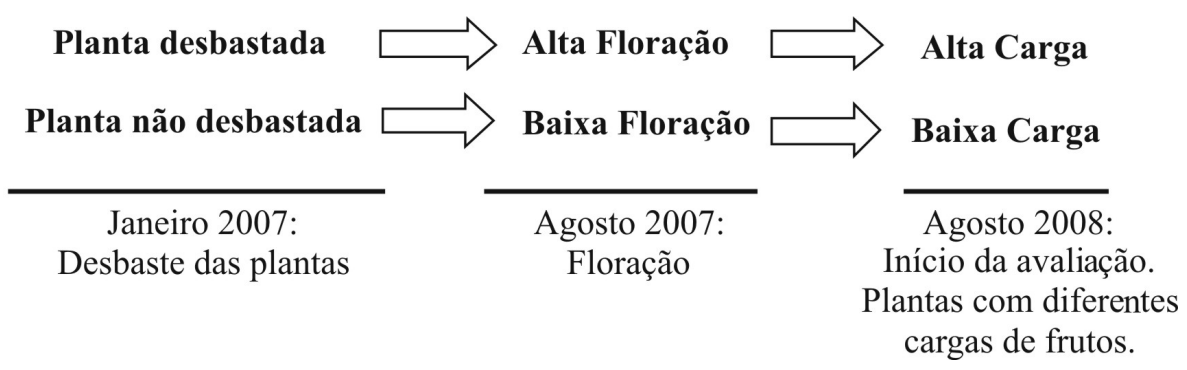

FIGURA 1 - Método experimental para indução da floração e frutificação em 2007 e 2008.

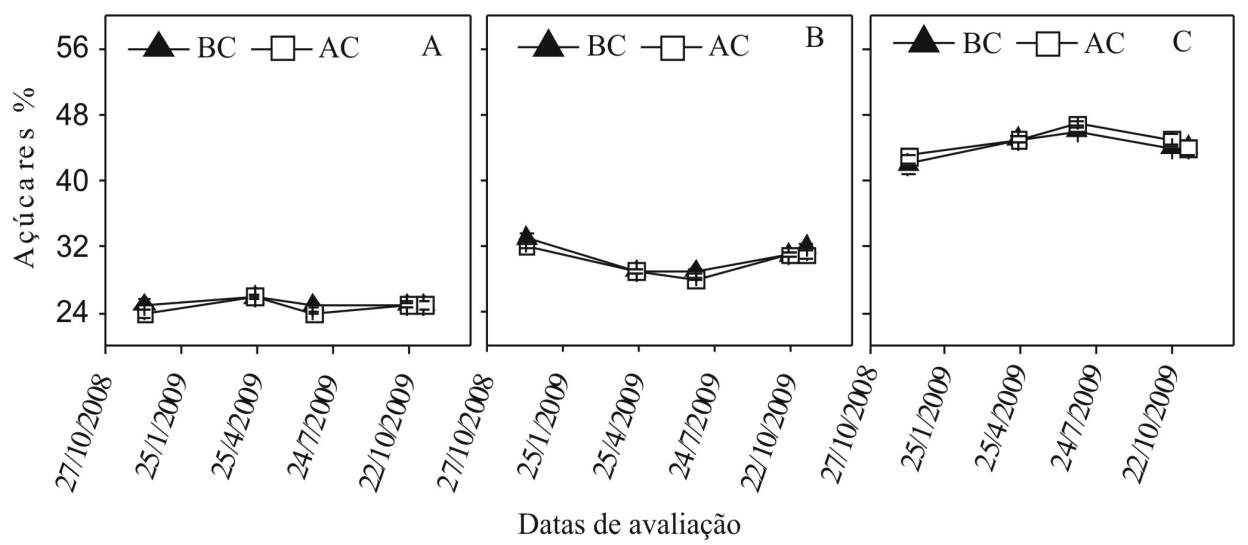

FIGURA 2 - Teor de glicose (A), frutose (B) e sacarose (C) no suco de laranjas 'Valência' em plantas com Baixa Carga de frutos (BC) e Alta Carga de frutos (AC) - Cordeirópolis-SP ano agrícola 2008/2009. Barras indicam erro-padrão $(n=5)$. 


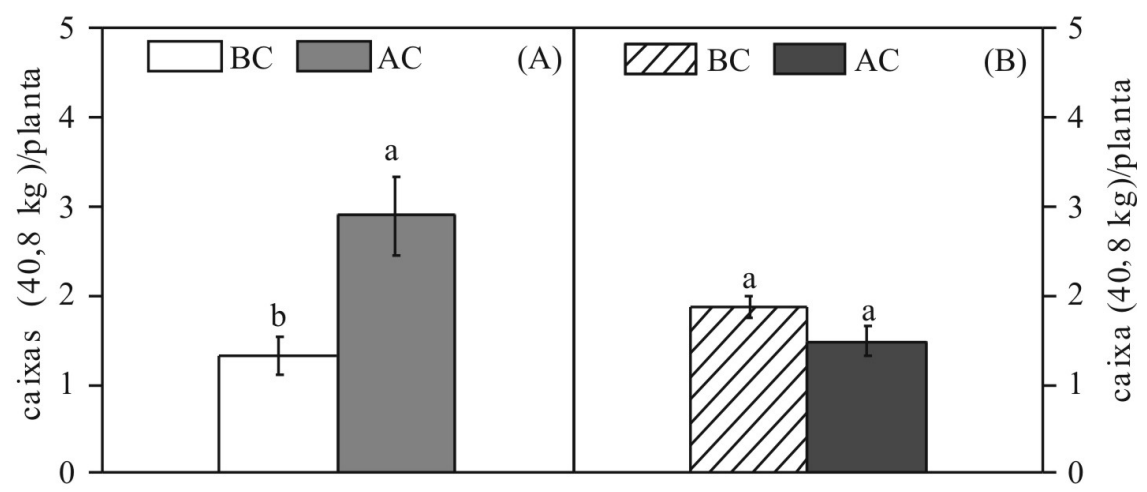

FIGURA 3 - Produção (caixas/planta) de laranjeiras 'Valência' em 2008 (A) e 2009 (B); em plantas BC (Baixa Carga de frutos) e AC (Alta Carga de frutos) - Cordeirópolis-SP. Barras indicam erro padrão $(n=5)$ e letras diferentes indicam diferenças estatísticas entre os tratamentos $(\mathrm{P} \leq 0,05)$.
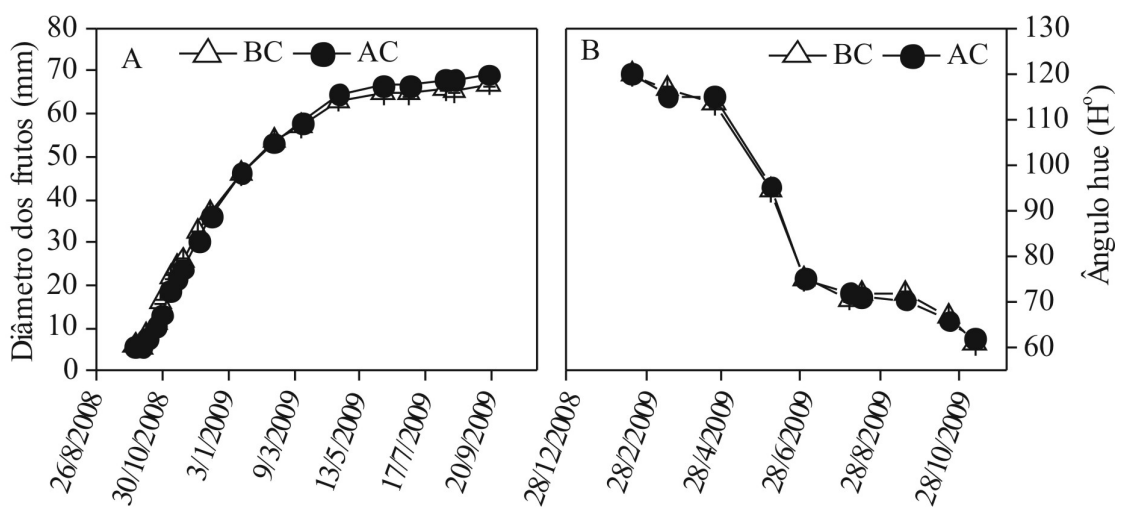

Datas de avaliação

FIGURA 4 - Diâmetro dos frutos (A) e cor da casca (B) de laranjas 'Valência' em plantas com Baixa Carga de frutos (BC) e Alta Carga de frutos (AC) ano agrícola de 2008/2009. Barras indicam erropadrão $(\mathrm{n}=5)$.

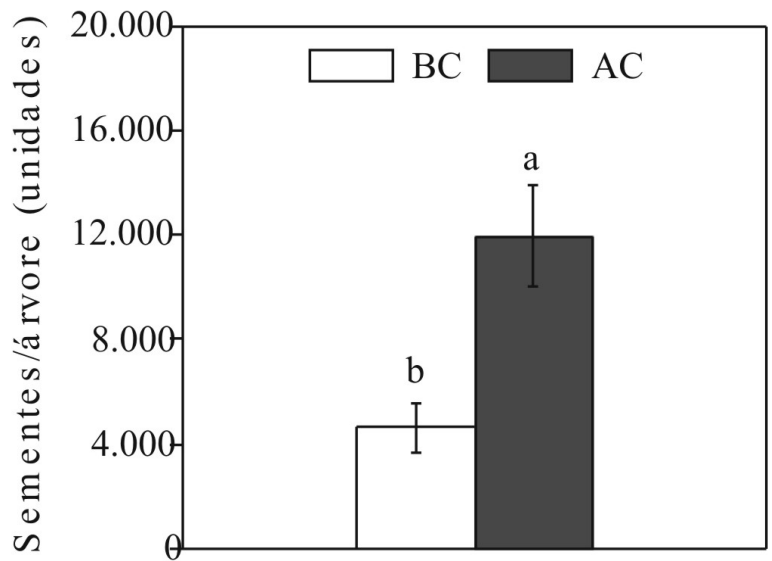

FIGURA 5 - Número de sementes/árvore de laranjeiras 'Valência' em plantas com Baixa Carga de frutos (BC) e Alta Carga de frutos (AC) - Cordeirópolis-SP, safra de 2008. Barras indicam erropadrão $(n=5)$ e letras diferentes indicam diferenças estatísticas entre os tratamentos $(\mathrm{P} \leq 0,05)$. 


\section{CONCLUSÃO}

Apesar de reduzir a massa do fruto, a diferença de carga pendente observada em laranjeira 'Valência' não influencia na qualidade dos frutos quando considerada a indústria citrícola como destino da fruta.

\section{REFERÊNCIAS}

BUSTAN, A.; GOLDSCHMIDT, E. Estimating the cost of flowering in a grapefruit tree. Plant, Cell and Environment.Oxford, v. 21, n.2, p.217-224, 1998.

CHITARRA, M.I.F.; CHITARRA, A.B. Pós-colheita de frutos e hortaliças: fisiologia e manuseio. Lavras: ESAL/FAEPE, 1990. 320 p.

DI GIORGI, F.; IDE, B.Y.; DIB, K.; MARCHI, R.J. ; TRIBONI, H.R. ; WAGNER, R.L. Contribuição ao estudo do comportamento de algumas variedades de citros e suas implicações agroindustriais. Laranja, Cordeirópolis, v. 11, n. 2, p. 567-612, 1990.

FIGUEIREDO, J. O. Variedades comerciais. In: RODRIGUEZ, O.; VIÉGAS, F.; POMPEU JR. J.; AMARO, A. A. Citricultura brasileira. 2. ed. Campinas: Fundação Cargill, 1991. p. 228-257.

GALLASH, P.T. Effect of time of harvest on alternate cropping yields and fruit quality of Valencia orange trees. Australian Journal of Experimental Agricultural and Animal Husbandry,Victoria, v. 18, n.92, p. 461-464, 1978.

GOLDSCHMIDT, E. E.; GOLOMB, A. The carbohydrate balance of alternate-bearing citrus trees and the significance of reserves for flowering and fruiting. Journal of the American Society for Horticultural Science, Alexandria, v.107, n.2, p.206-208, 1982.

GONZALEZ-FERRER, J.; AGUSTÍ, M.; GUARDIOLA, J.L. Fruiting pattern and retranslocation of reserves in Navelate and Washington navel oranges. In: INTERNATIONAL CITRUS CONGRESS, 6. 1984, São Paulo. Proceedings... Piracicaba: International Society of Citriculture, 1984. v.1, p.194-200.

GUARDIOLA, L. L.; MONERRI, C.; AGUSTI, M. The inhibitory effect of gibberelic acid on flowering in Citrus. Physiologia Plantarum, Copenhagen, v. 55, n. 2, p.136-142, 1982.

GUARDIOLA, J.L. Fruit set and growth. In: SECOND INTERNATIONAL SEMINAR ON CITRUS PHYSIOLOGY, 2, 1992. Bebedouro. Proceedings... São Paulo: International Society of Citriculture, 1992. p. 1-30.

IGLESIAS, D. J.; TADEO, F. R.; PRIMO-MILLO, E.; TALÓN, M. Fruit set dependence on carbohydrate availability in citrus tres. Tree Physiology, Victoria, v.23, n.3, p.199-204, 2003.

LADANIYA, M. S. Citrus fruit: biology, technology and evaluation. San Diego: Elsevier, 2008.558p.

MONSELISE, S.P.; GOLDSCHMIDT, E.E. Alternate bearing in fruit trees. Horticultural Reviews, New York v.4, n.1, p.128-173, 1982.

MOSS, G.I. Effect of fruit on flowering in relation to biennial bearing in sweet orange (Citrus sinensis). Journal of Horticultural Science, Ashford, v. 46, n. 1, p. 177-184, 1971.

NONINO, A.E. Variedades de laranjas para fabricação de sucos. Laranja, Cordeirópolis, v.16, n.1, p.119-132, 1995.

RODRIGO, M.J.; ZACARÍAS, L. Horticultural and Quality Aspects of Citrus Fruits. In: HUI, Y. H. (Ed.) Handbook of fruits and fruit processing. Iowa: Blackwell Publishing, 2006. p. 293-307.

RUFINI, J. C. M.; RAMOS, J.D. Influência do raleio manual sobre a qualidade dos frutos da tangerina 'Ponkan' (Citrus reticulata BLANCO). Ciência e Agrotecnologia, Lavras, v.26, n. 3, p.516-522, 2002.

SANZ, A.; MONERRI, C.; GONZÁLEZ-FERRER, J.; GUARDIOLA, J. L. Changes in carbohydrates and mineral elements in Citrus leaves during flowering and fruit set. Physiologia Plantarum, Copenhagen, v. 69, n.1, p.93-98. 1987.

STANCATO, G.C.; MAZZAFERA, P.; BUCKERIDGE, M.S. Effect of a drought period on the mobilization on non-structural carbohydrates, photosynthetic efficiency and water status in an epiphytic orchid. Plant Physiology and Biochemistry, Paris, v. 39 , n. 11, p. 1009-1016, 2001.

VU, J.C.V.; YELENOSKY, G.; BAUSHER, G. Photosynthetic activity in the flower buds of 'Valencia'orange (Citrus sinensis [L.] Osbeck). Plant Physiology, Rockville, v. 78, n. 2, p. 420-423, 1985.

WHEATON, T. A. Alternate bearing. In: CITRUS FLOWERING \& FRUITING SHORT COURSE, 1. , 1986, Flórida. Proceedings... Lake Alfred: CREC/ IFAS, 1986. Disponível em: <www.fcprac.ifas.ufl. edu/>. Acesso em: 15 jun. 2008. 